\title{
Effect of natural ageing on the properties of recycled polypropylene/ethylene vinyl acetate/wood flour composites
}

\author{
Caroline Barbosa da Silva ${ }^{1,}$ Andrea Bercini Martins ${ }^{1}$, André Luis Catto ${ }^{1}$, \\ Ruth Marlene Campomanes Santana ${ }^{1}$
}

\author{
${ }^{1}$ Laboratório de Materiais Poliméricos - LAPOL - Departamento de Engenharia de Materiais - UFRGS \\ Av. Bento Gonçalves, 9500 - Porto Alegre, RS, Brazil. CP: 15090, CEP 91501-970 \\ e-mail: carolina.barbosa@ufrgs.br, andrea.bercini@ufrgs.br; andrecatto@terra.com.br; ruth.santana@ufrgs.br
}

\begin{abstract}
Wood flour composites main applications are represented by outdoor furnishing. Therefore, it is important to evaluate their behavior under natural ageing conditions. This work aims to investigate the natural ageing impact on the mechanical, physical, thermal e morphological properties of recycled polypropylene/ethylene vinyl acetate/wood flour composites (PP/EVA/ITA). Samples were exposed to natural ageing for 12 months in Porto Alegre (BR). Mezilaurus itauba (ITA) wood flour was used at $30 \% \mathrm{w} / \mathrm{w}$. Results showed that PP filled wood flour retained a higher fraction of the original mechanical properties after natural ageing. Crystallinity degree for composites increased from 30.9 up to $37.5 \%$ Climatic conditions affected the colorimetric and morphological characteristics of composites, indicating that there was not only photo-degradation but also thermo-oxidative and hydrolytic degradation. In this way, the use of antioxidant additives and UV photo-absorbers is recommended to avoid stress-cracking, discoloration and loss the mechanical properties.
\end{abstract}

Keywords: Wood plastic composite; recycled PP; recycled EVA; natural ageing.

\section{INTRODUCTION}

With the growing consumer demands, leading to major issues of material availability and environmental sustainability, an increased awareness that non-renewable resources are becoming scarce and an inevitable dependence on renewable resources began to arise. In this context, the use of renewable materials as lignocellulosic fillers with thermoplastic polymers has recently increased. Due to large quantity of wood and polymer waste generated daily, the use of residual wood flour from wood processing with recycled thermoplastic matrix is an excellent alternative to replace the use plain wood, as it is less susceptible to moisture induced swelling, shrinking, and thermal degradation [1].

Wood plastic composites (WPC's) have been gaining considerable attention on international market due to their low density, good thermal insulation, sustainability and low price [2,3]. These materials can be used in indoor and outdoor applications, including windows and doorframes, interior panels in cars, railings, decking, cladding and fences [4]. Its dimensional stability tends to be better than that of the traditional wood products, thereby rendering them suitable for application in end-uses in humid and water front environments [5]. Furthermore, several companies are using wood plastic composites because of the increased stability and resistance to biological attack compared to traditional wood and solid lumber products [6].

It has been demonstrated that WPCs that are exposed to weathering may experience changes on its properties. The natural ageing is initiated by sunlight that is abundantly present in outdoor environment, especially by ultraviolet (UV) radiation. Photo-degradation of WPC, also understood as the ageing of the major components of WPC (wood and polymer), results from the combined effects of light, water, oxygen, and heat [7].

Several chemical reactions resulting in color/appearance change are induced by solar radiation. According to the mode of initiation, the following types of degradation can be distinguished: thermal, chemical, mechanical, and biological. The photodegradation of polyolefins is mainly caused by the introduction of chromophores functional groups, such as catalyst residues, hydroperoxide groups, carbonyl groups, and double bonds, during polymer manufacture. Photo-yellowing of weathered wood has been attributed to the breakdown of lignin into water soluble products, which eventually leads to the formation of chromophores 
groups such as carboxylic acids, quinones, and hydroperoxy radicals. The presence of chromophores in polymer and wood usually enhances the absorption of ultraviolet (UV) light, which later causes photodegradation of WPC $[7,8]$.

Although UV accelerated weathering procedures are widely used in polymer degradation studies

[4,9-12], there are not many works involving natural exposure. It happens due to the difficulty of reproduction and the long time it requires. The laboratory degradation analysis, using accelerated aging chamber, generally use standardized and controlled conditions. However, that are not equivalent to real situations of exposure or use, since is very difficult to simulate on laboratory the variability of natural elements such as temperature, radiation index, rainfall and wind [13].

Besides photodegradation, the polyolefins suffer thermal and mechanical degradation and also oxidation, especially in the transformation process as extrusion and injection that involve high rates of shear. For this reason, most polymers has already incorporated additive package as protection and modification of specific properties according to the type of application [14]. Another type of degradation that occurs in polymer material is stress-cracking, resulting in formation of fissures and cracks in the material [12].

In this way, the aim of this study was to investigate the degradation of post-consumer polypropylene/ethylene vinyl acetate-wood flour composites caused by natural ageing using a combination of thermal and mechanical properties, scanning electron microscopy and colorimetric measures. With this study, it is intended to determine their behavior from the point of view of stability in its use conditions. Moreover, in environmental terms, this study proposes an alternative to the reduction of the disposal problem in the environment both polymeric residues, non-recyclable, the lignocellulosic materials, considering the enormous potential value of the materials. Also contributing to the preservation of the environment by reducing the volume of solid waste disposed and by investing increasingly in developing of new materials, more sustainable and environmentally friendly.

\section{MATERIALS AND METHODS}

Wood flour from Mezilaurus itauba (ITA) specie was used as reinforcing filler in polymer matrix. Only particles that passed through a sieve of 32 and 24 Tyler series were used in this study, thus, the maximum particle average diameter was between 500-710 $\mu \mathrm{m}$. Wood flour ITA, without treatment, was supplied by a wood processing industry from Sinop - MT, Brazil.

Polypropylene with ethylene vinyl acetate (PP/EVA) from post-consumer bottle caps were used as matrix material. Ethylene vinyl acetate was present because the liner inside the bottle caps is made of EVA. Liner is a piece of material that sits between the cap and the bottle. Its primary function is to offer proper sealing of the product and often times it determines the closure's fit and function viability. The content of EVA on PP was $7 \%$ w/w.

The bottle caps with liners (PP/EVA) were transformed to powder using a cutting mill (Retsch SM300) at $1500 \mathrm{rpm}$. The powder was selected through a sieve system with particle size between 710-1000 $\mu \mathrm{m}$ (Tyler series 00 and 16).

PP/EVA powder and the wood flour, on a mass proportion of 70:30 w/w, were mixed using a Thermo Scientific Haake Rheomix OS at $180{ }^{\circ} \mathrm{C}, 60 \mathrm{rpm}$ and residence time of $5 \mathrm{~min}$. After mixing, the mixture was triturated to reduce particle size for further processing. Thereafter, the triturated mixture was molded in an injection molding machine (Thermo Scientific Haake, MiniJet II). The temperature adopted was $200{ }^{\circ} \mathrm{C}$, with a mold temperature of $40^{\circ} \mathrm{C}$ and 400 bar of pressure, producing tensile and flexural specimen tests.

The mechanical properties related to the materials tensile strength were analyzed according to ASTM D638 with crosshead speed of $5 \mathrm{~mm} / \mathrm{min}$ in a universal testing machine (INSTRON, model 3382). The specimen dimensions were according to type V. The three-point flexure test was carried out on an Instron Universal test machine (Model 3382) at a cross-head speed of $1.35 \mathrm{~mm} / \mathrm{min}$ until a maximum strain of $5.0 \%$ was reached, in accordance with ASTM D790 [16]. The size of samples was $63.5 \mathrm{~mm} \times 12.5 \mathrm{~mm} \times 3.3 \mathrm{~mm}$ (thickness). The testing was performed at room temperature of $25^{\circ} \mathrm{C}$, with five specimens of each formulation at each aging time, to obtain an average value.

Thermogravimetric analysis (TGA) of the samples were tested on a TA Instruments model Q50 instrument, under nitrogen atmosphere $(90 \mathrm{~mL} / \mathrm{min})$. The temperature range was from 25 to $800^{\circ} \mathrm{C}$ with a heating rate of $20^{\circ} \mathrm{C} / \mathrm{min}$.

Scanning electron microscopy (SEM) of the surface of non weathered and weathered materials exposed to different periods was conducted using a JEOL JSM 6060 Scanning Electron Microscope, operating at an acceleration voltage of $15 \mathrm{kV}$. The samples were gold metalized. 
Differential scanning calorimetry (DSC) thermograms were recorded by a TA Instruments model Q20. The samples were placed in an aluminum pan and were scanned from room temperature to $200{ }^{\circ} \mathrm{C}$ at a heating rate of $10^{\circ} \mathrm{C} / \mathrm{min}$ under nitrogen atmosphere. The degree of crystallinity of the composites was calculated using the following equation:

$$
x_{C}=\underset{\text { matif }}{\Delta x_{f}} \times 100
$$

Where $\Delta \mathrm{H}_{\mathrm{f}}$ is the heat of fusion for PP in the sample, $\Delta \mathrm{H}_{\mathrm{f}}{ }^{\circ}$ is the heat of fusion of $100 \%$ crystalline $\mathrm{PP}$ which is $209 \mathrm{~J} / \mathrm{g}$ (theorical melting entalphy) [17] and $\mathrm{w}$ is the weight fraction of PP in the composite.

The surface color of the composites was measured using a Spectro-Guide spectrophotometer, BYK, in accordance with ASTM D2244 [18]. Spectrometer's Spectro-Guide software transforms spectral data into CIELAB color coordinates ( $\mathrm{L}^{*}, \mathrm{a}^{*}$, and $\mathrm{b}^{*}$ ) based on a D65 light source. Lightness ( $\left.\mathrm{L}^{*}\right)$ and two chromaticity coordinates $\left(\mathrm{a}^{*}\right.$ and $\mathrm{b}^{*}$ ) were measured at three different positions on each. Also, it was measured of the gloss $(\mathrm{G})$ of the samples. An increase in $\mathrm{L}^{*}$ value means the color of the sample becomes lightening. A positive $a^{*}$ signifies a color shift toward red, and a negative $a^{*}$ signifies a color shift toward green. A positive $b^{*}$ signifies a shift toward yellow, and a negative $b^{*}$ signifies a shift toward blue.

The test was performed according to ASTM D1435 [19]. Specimens tests were exposed to natural sunlight outdoor in the north direction at $45^{\circ}$ inclination as can be seen on the Figure 1 . The geographical location was: latitude ( $30^{\circ} 05^{\prime}$ South); longitude (51 $11^{\prime}$ West), and altitude (174 $\left.\mathrm{m}\right)$ at Porto Alegre city, in the south of Brazil. This allowed normal incidence of solar radiation over the entire surface of the samples, for a total of 4, 8 and 12 months, between October of 2014 to October 2015. During the natural weathering test were monitored the average of UV radiation index, temperature, and the rainfall were provided by the CPTED-INPE (Center for weather and climate studies - National Institute for Space Research - Brazil).

Figure 1 shows the climatic conditions (maximum temperature and maximum UV index (UVI); moisture and average total monthly rainfall) in the total period studied. It was observed that the highest temperatures occurred in the months of November 2014 to March 2015, but the maximum temperature on January 2015. Regarding precipitation, the period evaluated has $170 \mathrm{~mm}$ on average from October 2014 to May 2015, and between June to October 2015 the frequency of rainfall was higher, reaching $310 \mathrm{~mm}$ values. As result, the relative humidity was high in this period, between 70 to $90 \%$. Regarding the UVI, the values were high during the spring and summer, reaching maximum values of 12 , classified as extreme.

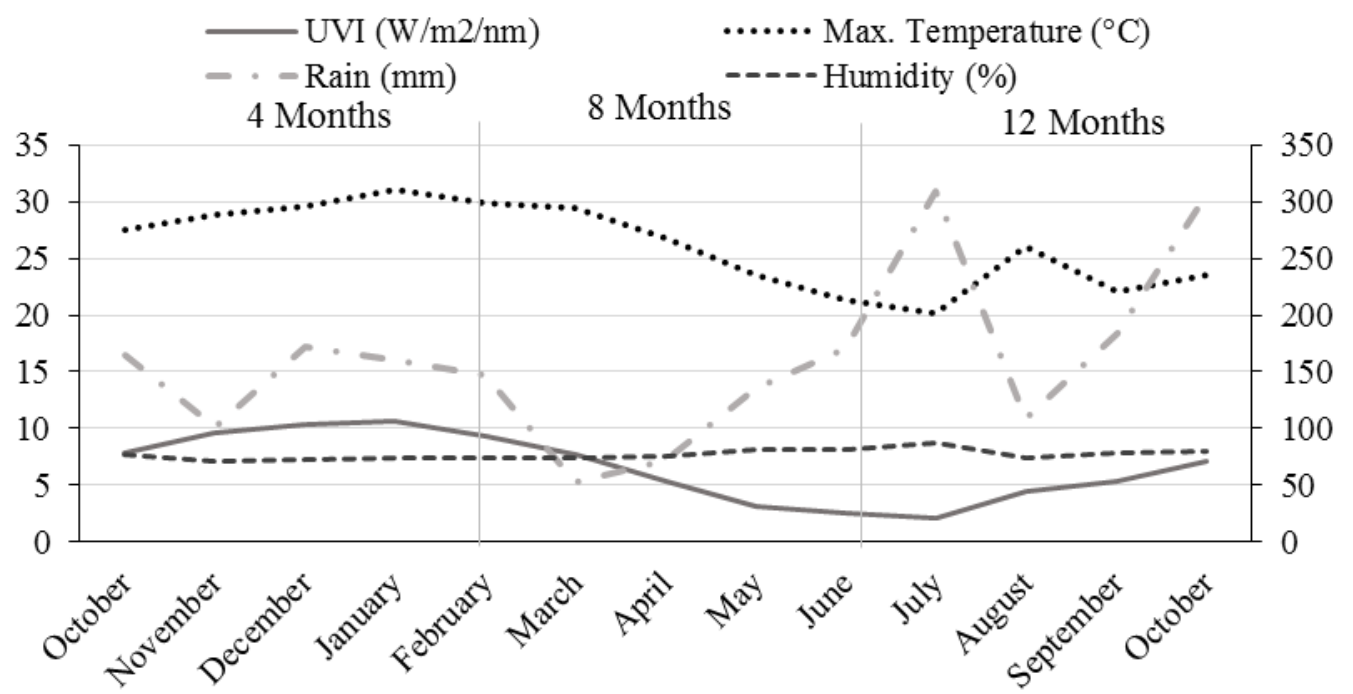

Figure 1: Monthly average maximum temperature and maximum UV Index (UVI) on the left axis and moisture and average total monthly rainfall on the right axis for Porto Alegre city (BR), in the years 2014-2015.

\section{RESULTS AND DISCUSSION}

\subsection{Influence of natural ageing on the mechanical properties}


Table 1 shows tensile properties of all studied material before and after natural ageing by 4, 8, and 12 months. Since the climatic conditions during natural ageing were the only factor acting on the samples, it is possible to affirm that the combined effect of rain, humidity and solar radiation indeed negatively affected the mechanical properties of samples.

Table 1: Mechanical properties of all studied samples at each stage. 2014-2015.

\begin{tabular}{|c|c|c|c|c|c|}
\hline \multirow{2}{*}{ SAMPLE } & \multicolumn{3}{|c|}{ TENSILE } & \multicolumn{2}{|c|}{ FLEXURE } \\
\hline & $\begin{array}{c}\text { Tensile Modulus } \\
\text { (MPa) }\end{array}$ & $\begin{array}{l}\text { Tensile strength } \\
\text { at break (MPa) }\end{array}$ & $\begin{array}{c}\text { Elongation at } \\
\text { break }(\%)\end{array}$ & $\begin{array}{l}\text { Flexural modulus } \\
\text { (MPa) }\end{array}$ & $\begin{array}{c}\text { Flexural strength } \\
\text { at } 5 \% \text { strain (MPa) }\end{array}$ \\
\hline $\mathrm{PP} / \mathrm{EVA}$ & $483 \pm 123$ & $31 \pm 1.13$ & $615 \pm 24$ & $913 \pm 12$ & $28.6 \pm 0.5$ \\
\hline $\mathrm{PP} / \mathrm{EVA} 4 \mathrm{M}$ & $968 \pm 70$ & $12 \pm 4.00$ & $60 \pm 0.14$ & $886 \pm 23$ & $27.0 \pm 0.6$ \\
\hline $\mathrm{PP} / \mathrm{EVA} 8 \mathrm{M}$ & $792 \pm 66$ & $10 \pm 2.70$ & $60 \pm 0.23$ & $1048 \pm 46$ & $30.1 \pm 0.8$ \\
\hline $\mathrm{PP} / \mathrm{EVA} 12 \mathrm{M}$ & $1095 \pm 38$ & $11 \pm 0.61$ & $18 \pm 0.08$ & $767 \pm 68$ & $25.9 \pm 0.3$ \\
\hline PP/EVA/ITA & $908 \pm 204$ & $19 \pm 1.63$ & $18 \pm 3.33$ & $1702 \pm 39$ & $34.8 \pm 0.7$ \\
\hline $\mathrm{PP} / \mathrm{EVA} / \mathrm{ITA} 4 \mathrm{M}$ & $1088 \pm 151$ & $15 \pm 2.43$ & $13 \pm 3.15$ & $1719 \pm 46$ & $35.7 \pm 1.1$ \\
\hline PP/EVA/ITA $8 \mathrm{M}$ & $676 \pm 106$ & $16 \pm 2.76$ & $13 \pm 2.35$ & $1581 \pm 33$ & $31.4 \pm 0.6$ \\
\hline PP/EVA/ITA 12M & $1204 \pm 251$ & $11 \pm 3.13$ & $11 \pm 1.85$ & $1421 \pm 90$ & $30.7 \pm 1.9$ \\
\hline
\end{tabular}

For a better understanding of mechanical properties changes, the relative values were plotted in Figure 2, 3 and 4. Where, the values have been reported in dimensionless form - value at a given time divided by the value for the non-ageing samples (Table 1) - to better highlight the kinetics of the variations of the properties.

Elastic modulus values presented an expected increase of PP/EVA with the exposure time as can be seen on Figure 2. The natural ageing induced an increase of more of $100 \%$ (from $483 \mathrm{MPa}$ to $1095 \mathrm{MPa}$ ), which can be explained by the promotion of PP crystallization induced by shorter macromolecular chains resulting from a predominant chain scission phenomenon occurring during the weathering. With respect to the elastic modulus of the composite, the increase was less pronounced, indicating that PP filled wood flour has greater stability module along the evaluated time. In the period of eight months there was a slight decrease in elastic modulus, that may have been influenced by low temperatures, low UVI e high rainfall.

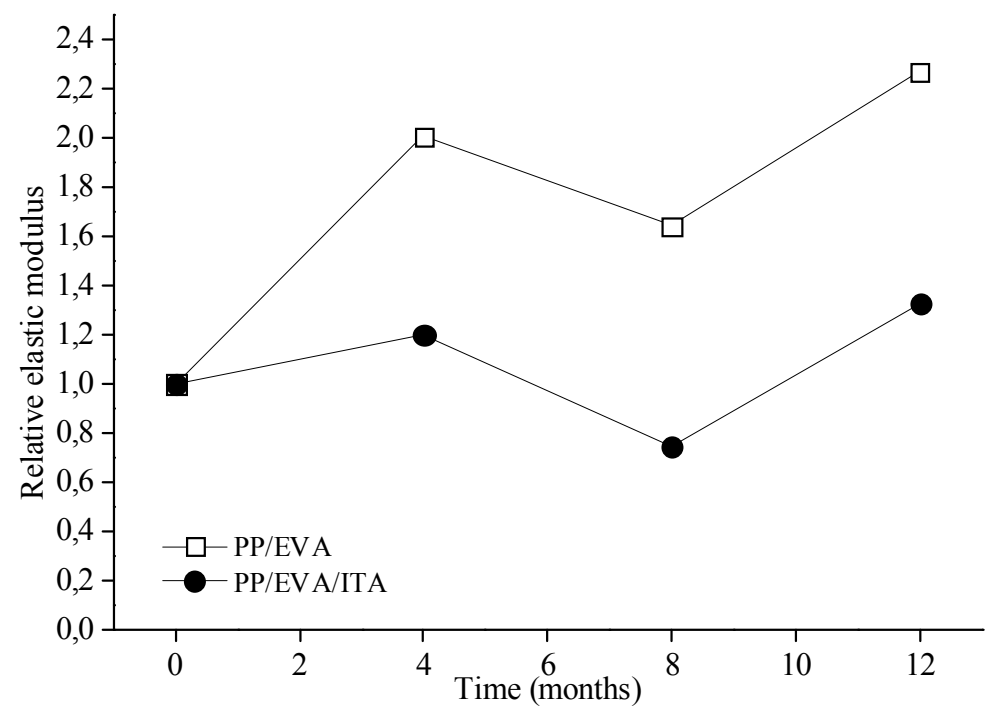

Figure 2: Dimensionless elastic modulus as a function of natural ageing time. 2014-2015.

The tensile strength at break decreases significantly in the neat PP/EVA, because of the chain scission reaction induced by the irradiation. However, thanks to the stiffening effect of the filler, it stays higher in the filled samples (Fig.3). The effect of natural ageing was also pronounced on elongation at break. The decrease of 
deformability, upon first four months of exposure, was $90 \%$ to PP/EVA when compared with the nonweathering samples. In relation to the composite, the decrease was $27 \%$, which remained constant until 8 months, probably influenced by humidity (due to higher frequency of rainfall in this period). According to Butylina et al [16], water has a detrimental effect on the weather ability of wood-polymer composites. Water accelerates the oxidation reaction and causes swelling of the wood fiber and the degradation of hydrophobic components (such as polyolefin and/or lignin) at the surface of the composite. Concerning the tensile elongation, in Soccalingame et al [14] study, the artificial weathering also induced $50 \%$ of decrease on wood flour and PP composites. The conditions of the artificial weathering were equal to a range of 2-3 months of natural exposure considering UV radiations only (300-400 $\mathrm{nm})$.
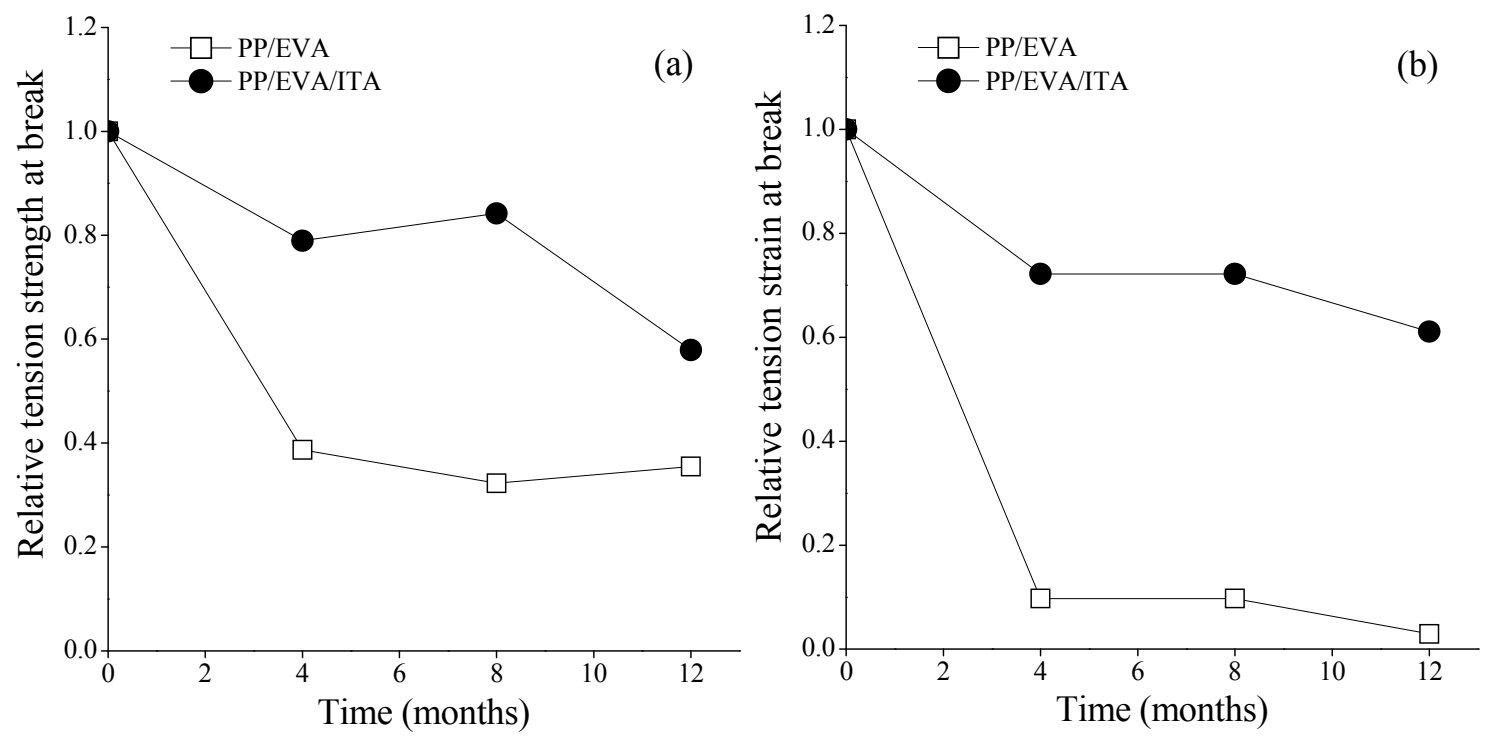

Figure 3: Dimensionless tensile strength and strain at break as a function of natural ageing time. 2014-2015.

The flexural performance in PP-EVA before and after 12 months of natural ageing were lower than the composites, especially in the flexure modulus as also listed in Table 1 . The flexural strength of the composites decreased with longer exposure time. This may be due to increased swelling of wood flour by humidity, especially in periods of higher frequency of rain precipitation that caused microcracks in the matrix and decreases the efficiency of stress transfer from wood flour to plastic matrix, decreasing the flexural strength. The loss of the flexural modulus is partly due to the negative effect of moisture penetration during exposure time [20].

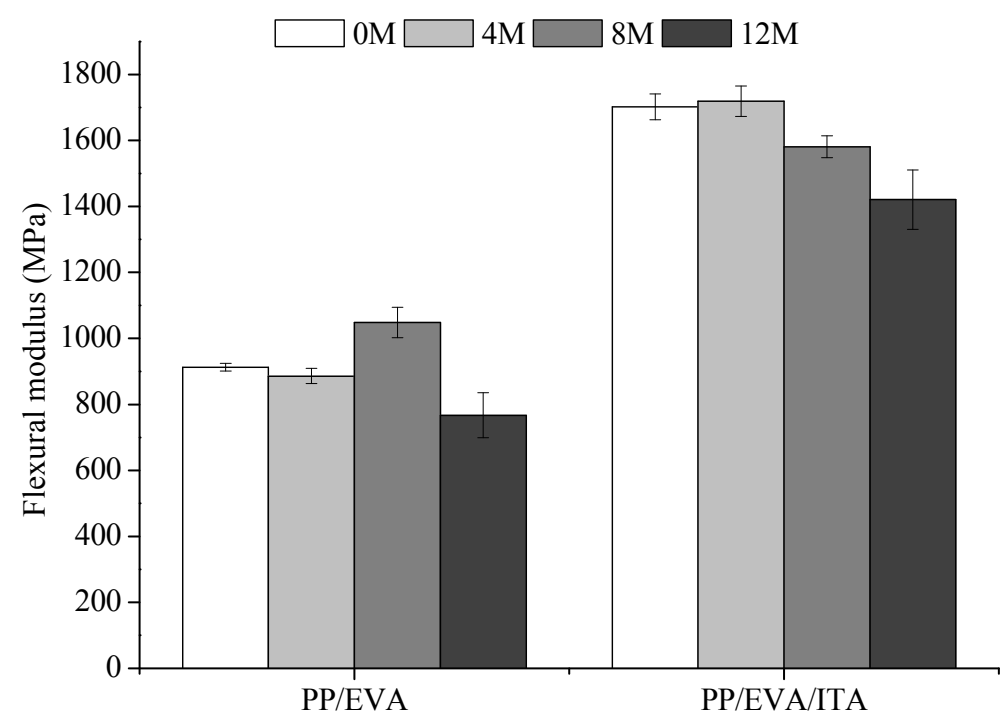


Figure 4: Flexural modulus of PP/EVA and the composites PP/EVA/ITA. 2014-2015.

\subsection{Influence of natural ageing on the morphology changes}

The micrographs in Figure 5 show the surface of non weathered and weathered materials exposed to different periods. The SEM results shows that the surfaces of the non-weathered composites were relatively smooth, and a polymer layer over the wood particles was evident. After 4 months of outdoor weathering, marks of surface degradation were detected in all samples. Weathering resulted in the appearance of several cracks and micro fissures. These images show clearly that the photo-degradation caused by UV solar radiation occured on the samples surface. According to Butylina et al [21], both polypropylene photo-degradation and wood particle swelling can cause formation of cracks on the surface of composites.

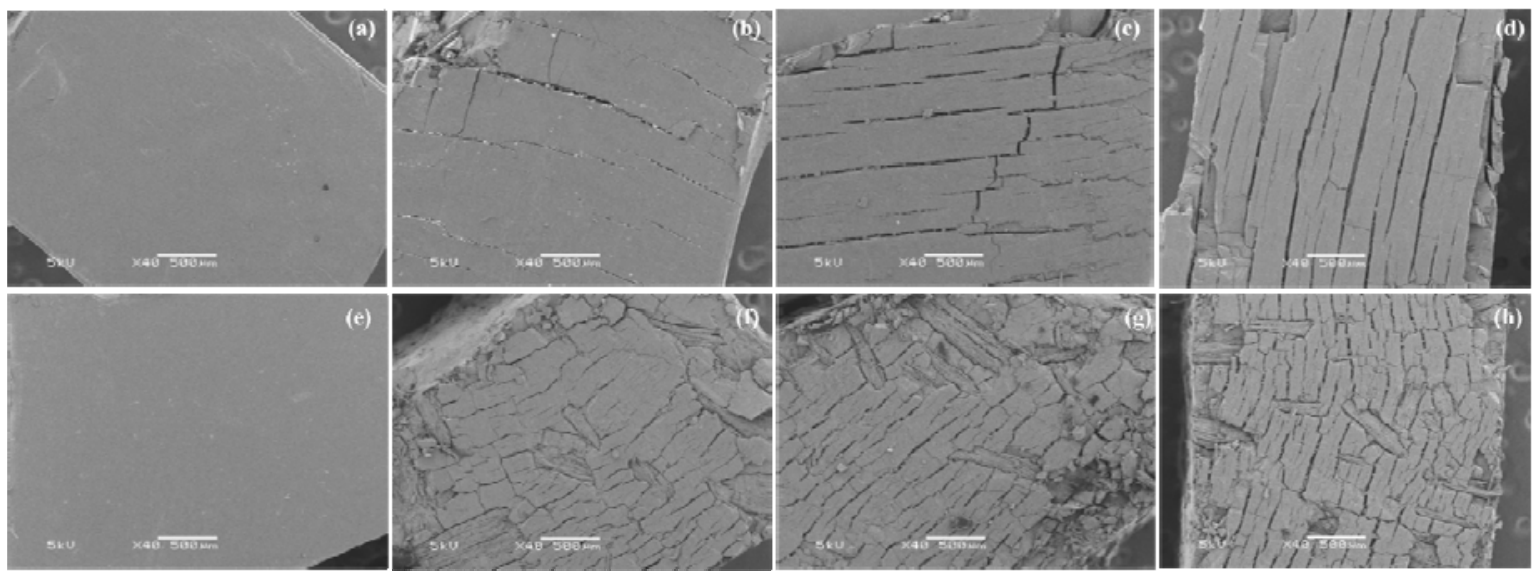

Figure 5: SEM images of the surfaces of PP/EVA before and after exposure by 4, 8 and 12 months (a, b, c and d, respectively) and composites PP/EVA/ITA before and after exposure by 4, 8 and 12 months (e, f, $g$ and h, respectively), (40x magnification). 2014-2015.

However, there are morphologies of surface differentiable from the eighth month, where it is possible to verify that PP/EVA samples showed a greater propagation cracks, deeper and mono-directed (extrusion direction). On the other hand, observing the PP/EVA/ITA surface, its cracks appeared to be less deep, perhaps the vegetable fiber presence has acted as an obstacle, obstructing the cracks propagation. Also, PP/EVA/ITA surface cracks were seem to be more superficial, so the integrity on the specimen interior was maintained. It could explain why this composite has presented better mechanical performance stability under natural weathering.

It is believed that this greater appearance of cracks on the sample surface is a product of degradation by stress cracking, caused by the impact of rain precipitation on the sample surface, especially in those periods where the rain rate was greater, as shown in Figure 1. Added to this, it is noteworthy that these cracks could have favored the entry of water in contact with vegetable fiber, causing swelling and possible hydrolytic degradation $[7,11,20,22]$. The oxidation reactions occur preferentially in the amorphous region of the polymer due to increased permeability of oxygen in this region and the segregation of chromophore impurities by the crystals during their formation. With the chain scissions, a release of chain segments in amorphous region that not crystallized during the original solidification process. These segments can rearrange into a crystalline phase if they have sufficient mobility, which is called chemo-crystallization [23]. The literature reported the occurrence of this phenomenon when the polypropylene (PP) is subjected to photo-degradation [22]. With the chemo-crystallization, there was contraction of nearest layers of surface and the formation of cracks. This chemo-crystallization of polymer, also known as stress cracking, which is the contraction of the more superficial layers forming cracks and therefore this effect led to the occurrence of other forms of degradation and hydrolytic degradation, resulting of water permeability, biodegradation, the presence of microorganisms in the environment, and other chemical degradation by the presence of acids and other chemicals in rainwater.

\subsection{Influence of natural ageing on the thermal properties}

Table 2 shows the melting temperature $(\mathrm{Tm})$, melting enthalpy $(\Delta \mathrm{Hf})$ and crystallinity degree $(\mathrm{Xc})$ of $\mathrm{PP}$ 
from composites before and after natural ageing obtained by DSC. It was observed that natural ageing did not affect the melting temperature of recycled polypropylene filled with wood flour. However, it was observed a pronounced increase of enthalpy values and degree of crystallinity after four months of natural ageing, probably influenced by high temperatures and high UV radiation as shown in Fig. 1. This result confirms the increase of elastic modulus shown in Table 1. However with eight months of exposure, there was a decrease of these parameters. This fact can be correlated with moisture presence, which could have worked as plasticizer, difficulting the crystallization and decayed the elastic modulus of the samples, as already discussed on section 3.1. Beg and Pickering [24] suggested that the reduction of crystallinity for polypropylene in composites after weathering was caused by swelling of the composites by absorbed water.

Table 2: Melting temperature (Tm), melting enthalpy $\left(\Delta \mathrm{H}_{\mathrm{f}}\right)$ and crystallinity $(\mathrm{Xc})$ of the PP wood flour composites over exposure time. 2014-2015.

\begin{tabular}{cccc}
\hline PP/EVA/ITA & $\mathbf{T}_{\mathrm{m}} \mathbf{P P}\left({ }^{\circ} \mathbf{C}\right)$ & $\boldsymbol{\Delta H}_{\mathbf{f}}(\mathbf{J} / \mathbf{g})$ & $\mathbf{X}_{\mathbf{c}}(\%)$ \\
\hline $0 \mathrm{M}$ & 163 & 45.13 & 30.8 \\
$4 \mathrm{M}$ & 160 & 57.96 & 39.6 \\
$8 \mathrm{M}$ & 162 & 43.71 & 29.9 \\
$12 \mathrm{M}$ & 163 & 54.83 & 37.5 \\
\hline
\end{tabular}

Finally, it can be observed a proximally $20 \%$ increase in the crystallinity ratio from 30.8 to $37.5 \%$ for PP/EVA/ITA before and after ageing, respectively. This behavior was attributed to a chain scission which facilitates the packaging of smaller chains thus forming larger amount of smaller crystalline phases, as mentioned before by Stark and Matuana [8]. Chaochanchaikul et al [12] studied the influence of lignin component of wood on the photodegradation of high-density polyethelyne (HDPE) in wood/HDPE composites. They showed that the percentage of crystallinity increased as function of UV weathering time.

Figure 6 shows changes in the thermal history of PP/EVA/ITA before and after natural aging in evaluated periods. Before exposure, it was identified the presence of two endothermic events, corresponding to melting from EVA $\left(90^{\circ} \mathrm{C}\right)$ and $\mathrm{PP}\left(163{ }^{\circ} \mathrm{C}\right)$. After four months of exposure, there was a subtle enlargement of the first peak, probably by the releasing of extractives with low mass molar from the vegetable fiber. After eigth months of exposure there was a greater extension and intensity in the first peak, probably due to the larger amount of water content in the sample, due to the greater rainfall period. Finally, after 12 months of exposure was possible to distinguish three small endotherms peaks before melting the PP, that could be related to the secondary recrystallization of short polymer segments produced by chain-breaking reactions on polypolypropylene after natural ageing. This behavior was also observed by López-Naranjo et al [25], who observed that because of accelerated weathering new thermal energy absorption peaks (shoulders at about 110 ${ }^{\circ} \mathrm{C}$ ) appeared on their material.

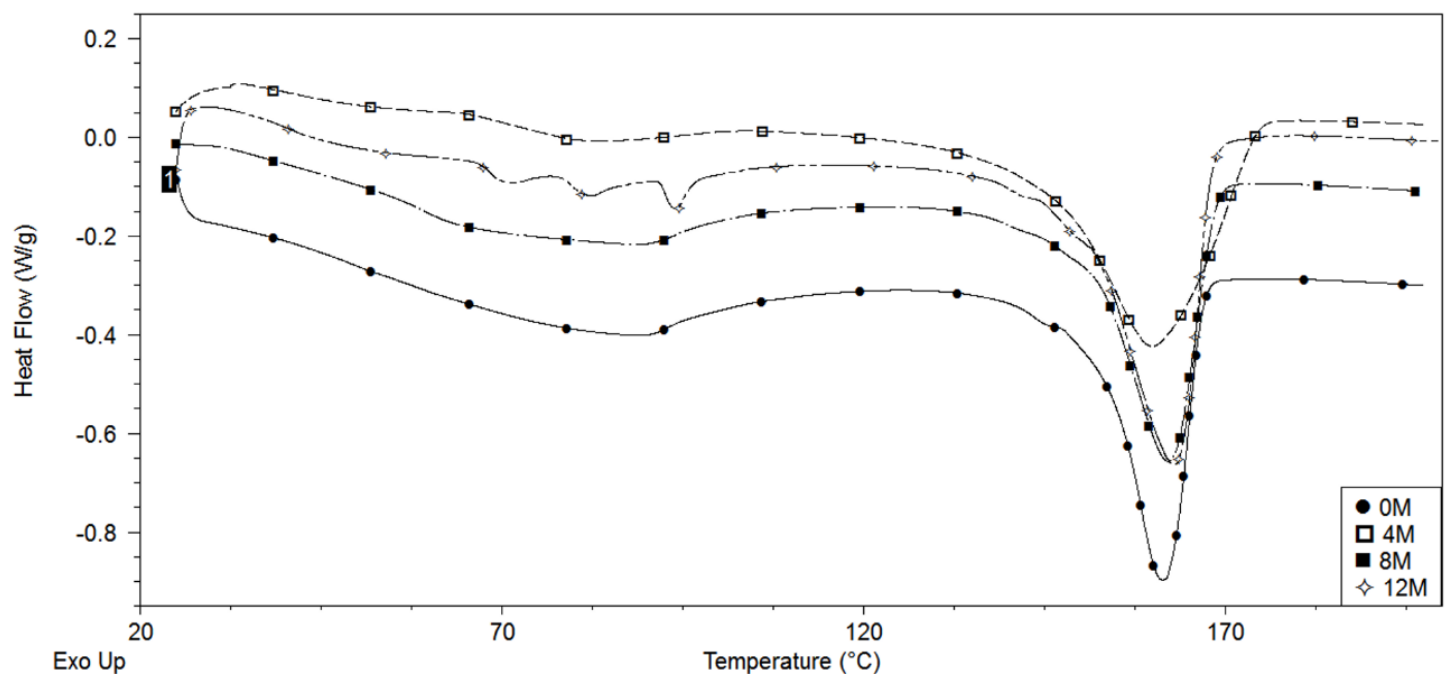


Figure 6: DSC comparative curves of the PP/EVA/ITA before and after exposure by 4, 8 and 12 months. 2014-2015.

In Figure 7 are shown comparative TGA curves of the composites before and after natural ageing and Table 3 shows the TGA numeric results. It was possible to verify the presence of five events of decomposition: the first corresponding to water evaporation and extractives of lower molar mass; the second to hemicellulose; the third to cellulose and vinyl acetate from EVA; the fourth due to PP matrix and a fifth because of the presence of higher molar mass fraction of lignin. Also is observed a difference in the composite ash content, where before exposure there was a greater amount, and after 8 and 12 months it had a pronounced loss, which indicates that the composites underwent complete leaching of inorganic salts from the eighth month of exposure.

Table 3: TGA results of composites before and after natural ageing, where $\mathrm{m} / \mathrm{m}$ is the mass loss percentage and $\mathrm{Tp}\left({ }^{\circ} \mathrm{C}\right)$ is the maximum peak temperature component degradation. 2014-2015.

\begin{tabular}{|c|c|c|c|c|c|c|c|c|c|c|c|c|}
\hline \multirow{2}{*}{$\begin{array}{c}\text { PP/EVA/ } \\
\text { ITA }\end{array}$} & \multirow{2}{*}{$\begin{array}{c}\begin{array}{c}\text { Loss, } \\
\mathbf{5 \%}\end{array} \\
{ }^{\circ} \mathbf{C}\end{array}$} & \multicolumn{2}{|c|}{$1^{\text {st }}$ Event } & \multicolumn{2}{|c|}{$2^{\text {nd }}$ Event } & \multicolumn{2}{|c|}{$3^{\text {st }}$ Event } & \multicolumn{2}{|c|}{$4^{\text {th }}$ Event } & \multicolumn{2}{|c|}{$5^{\text {th }}$ Event } & \multirow{2}{*}{$\frac{\text { Ash }}{\%}$} \\
\hline & & $\mathbf{m} / \mathbf{m}$ & $\begin{array}{c}\mathrm{Tp} \\
\left({ }^{\circ} \mathrm{C}\right)\end{array}$ & $\mathrm{a} / \mathrm{m}$ & $\begin{array}{l}\text { Tp } \\
\left({ }^{\circ} \mathbf{C}\right)\end{array}$ & $\mathbf{m} / \mathbf{m}$ & $\begin{array}{c}\text { Tp } \\
\left({ }^{\circ} \mathrm{C}\right)\end{array}$ & $\mathbf{m} / \mathbf{m}$ & $\begin{array}{l}\text { Tp } \\
\left({ }^{\circ} \mathrm{C}\right)\end{array}$ & $\mathbf{m} / \mathbf{m}$ & $\begin{array}{l}\text { Tp } \\
\left({ }^{\circ} \mathrm{C}\right)\end{array}$ & \\
\hline $0 \mathrm{M}$ & 301 & & 86 & 5 & 283 & 17 & 372.3 & 67 & 475 & 1. & 544 & $\overline{6.6}$ \\
\hline $4 \mathrm{M}$ & 297 & 1. & 77 & 4. & 277 & 14 & 363.5 & 74 & 473 & 1. & 525 & 3.9 \\
\hline $8 \mathrm{M}$ & 294 & 1.6 & 109 & 4. & 275 & 13.5 & 362.8 & 74.0 & 463 & 6 & 626 & 0.7 \\
\hline $12 \mathrm{M}$ & 292 & 1.8 & 90 & 4.3 & 309 & 17.4 & 373.7 & 68.4 & 467 & 7.4 & 642 & 0.4 \\
\hline
\end{tabular}


(a)

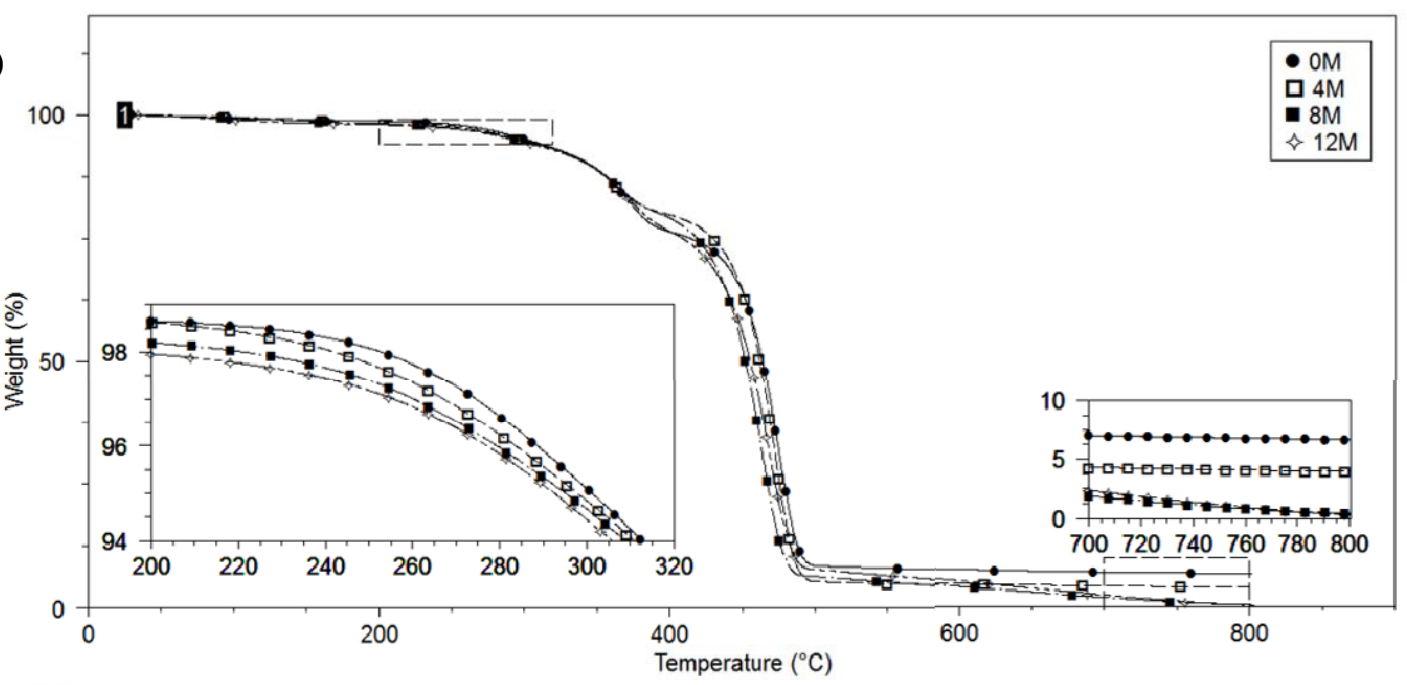

(b)

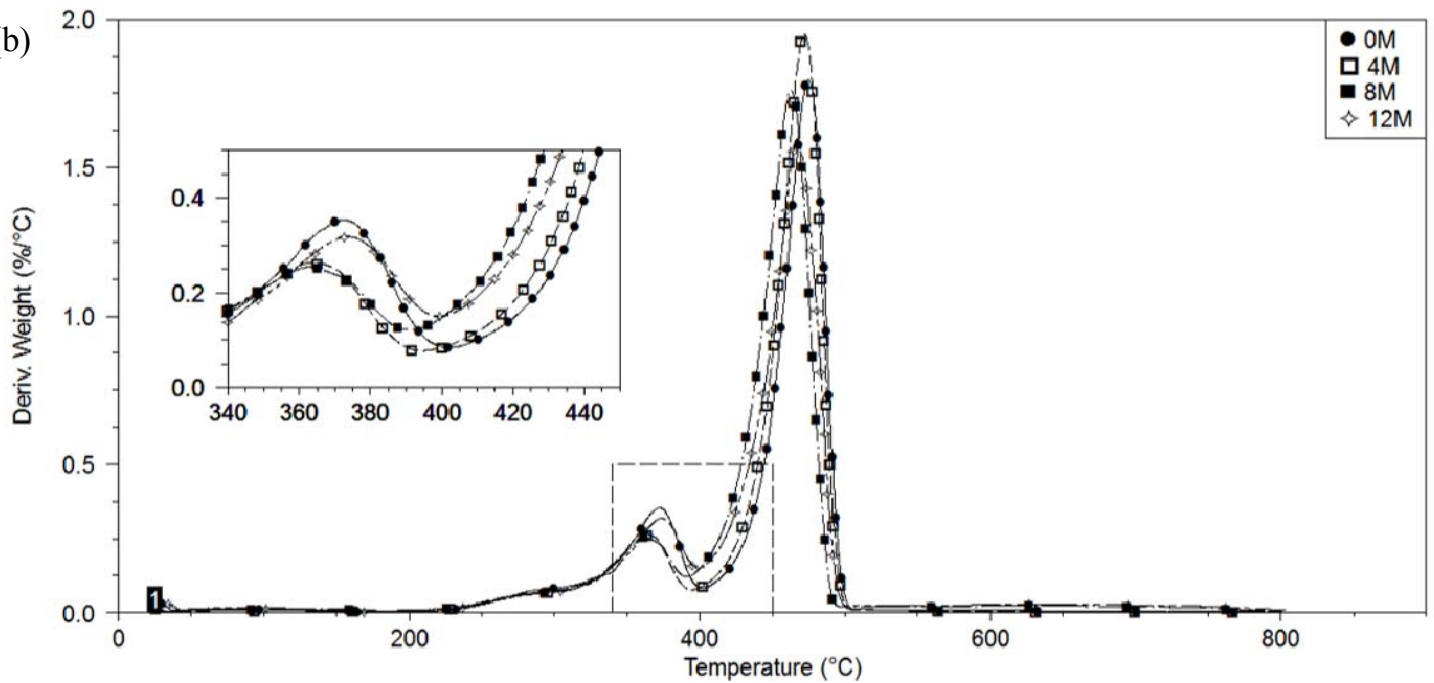

Figure 7: Curves of TGA and DTG of PP/EVA/ITA before and after exposure by 4, 8 and 12 months. 2014-2015.

A study of different wood species found that the degradation of hemicellulose takes place between $170-380{ }^{\circ} \mathrm{C}$, cellulose between $280-400{ }^{\circ} \mathrm{C}$ and the lignin begins at around $170{ }^{\circ} \mathrm{C}$ and extending above $600{ }^{\circ} \mathrm{C}$ [26]. The EVA copolymer suffers by being a two-step degradation: the first at about $330-450{ }^{\circ} \mathrm{C}$, which is where occurs the degradation of the vinyl acetate and the second in the range of $450-520{ }^{\circ} \mathrm{C}$ which degrades the olefin part of the copolymer. Since PP presents only a degradation stage and a peak degradation temperature of around $400-460{ }^{\circ} \mathrm{C}[27]$.

From these references a better understand of composite degradation stages could be possible. In first stage there is evaporation of water and terpenes characteristic of the timber; second stage the decomposition of hemicellulose and near the end of its decomposition; third stage the beginning of the decomposition of EVA with cellulose. In the fourth stage at approximately $475^{\circ} \mathrm{C}$ is the highest peak of the DTG corresponding degradation of PP and in the fifth stage is observed the degradation of the portion of the lignin. The ash content, probably silicon oxide, inorganic salt found in the woods, especially in Mezilaurus itauba, which is responsible for protection against moisture. In Table 3 are showed the values of the temperatures and mass loss in each decomposition stages and the ash. With respect to thermal stability of the composites (determined by mass loss in 5\%) [6], it is observed that the most stable composites were those not exposed to natural aging and the most unstable were that after 12 months exposure to weathering, results expected, confirming the results of the mechanical and morphologic properties.

\subsection{Influence of natural ageing on the physical properties}

Colorimetric changes and loss of gloss of the matrix and their composites were also monitored in the evaluated period, images of sample surface are shows on Figure 8 and the colorimetric results are gathered in Table 
4. The L* values of weathering da matrix did not presented significant changes compared to the non-aged sample. In the case of the composites, there was an increase of whitish after the exposure. In relation to colorimetric parameters $a^{*}$ and $b^{*}$, the matrix showed pronounced changes in the value of $b *$, which had an increase of yellowing, and a small loss of green color. There was a decrease in the composites of the parameters $\mathrm{a} *$ and $\mathrm{b} *$, indicating a discoloration effect (loss of red and yellowish color). The color fading of composites was attributed to photodegradation or photobleaching of lignin in the wood flour. The discoloration of the weathered samples could be attributed to the photo-oxidation of lignin [11]. Soccalingame et al. [14] also observed that the weathering induces a wood particle bleaching and a protrusion of these particles at the surface with many cracks. This results were also observed for Chaochanchaikul et al. [12].

Table 4: Colorimetric analysis result for the composites before and after ageing. 2014-2015.

\begin{tabular}{lcccc}
\hline SAMPLES & \multicolumn{1}{c}{$\mathbf{L}^{*}$} & $\mathbf{a}^{*}$ & $\mathbf{b}^{*}$ & Gloss \\
\hline PP/EVA & $77.40 \pm 0.4$ & $-12.2 \pm 0.8$ & $-7.90 \pm 0.9$ & $34.48 \pm 3.2$ \\
PP/EVA 4M & $77.11 \pm 1.5$ & $-10.8 \pm 1.1$ & $1.84 \pm 0.8$ & $23.31 \pm 9.3$ \\
PP/EVA 8M & $73.79 \pm 0.7$ & $-10.20 \pm 1.3$ & $1.64 \pm 1.4$ & $16.22 \pm 0.6$ \\
PP/EVA 12M & $73.98 \pm 1.7$ & $-8.44 \pm 0.9$ & $2.61 \pm 0.8$ & $16.70 \pm 2.8$ \\
\hline PP/EVA/ITA & $39.29 \pm 0.8$ & $2.8 \pm 0.3$ & $4.02 \pm 8.7$ & $25.59 \pm 8.7$ \\
PP/EVA/ITA 4M & $57.40 \pm 0.8$ & $0.1 \pm 0.1$ & $2.07 \pm 1.8$ & $6.32 \pm 1.8$ \\
PP/EVA/ITA 8M & $59.28 \pm 0.5$ & $-0.37 \pm 0.05$ & $1.97 \pm 0.2$ & $4.25 \pm 0.2$ \\
PP/EVA/ITA 12M & $59.66 \pm 0.8$ & $-0.21 \pm 0.2$ & $2.51 \pm 2.4$ & $5.03 \pm 2.4$ \\
\hline
\end{tabular}

It is also seen that PP/EVA had a higher brightness value than the composites, probably due to the presence of vegetable fiber, what creates irregularities on the sample surface. In PP-EVA samples there was a more pronounced loss $(\sim 50 \%)$ from exposed in 8 months, caused by the greater crack propagation; since the composites showed a greater loss in the fourth month $(75 \%)$, due to the higher roughness and cracks on the sample surface as has been shown in the micrographs of Figure 4.

According to published studies on the weathering of wood plastic composites from Homkhiew et al. [20], the addition of wood flour into plastics accelerates the photodegradation of wood plastic composites. However, when 1 wt \% of UV stabilizer was used on PPr/EVAr/WF, the composites had smaller changes in gloss and smaller relative flexural strength and modulus than without UV stabilizer, due to reduced photodegradation of polymer.

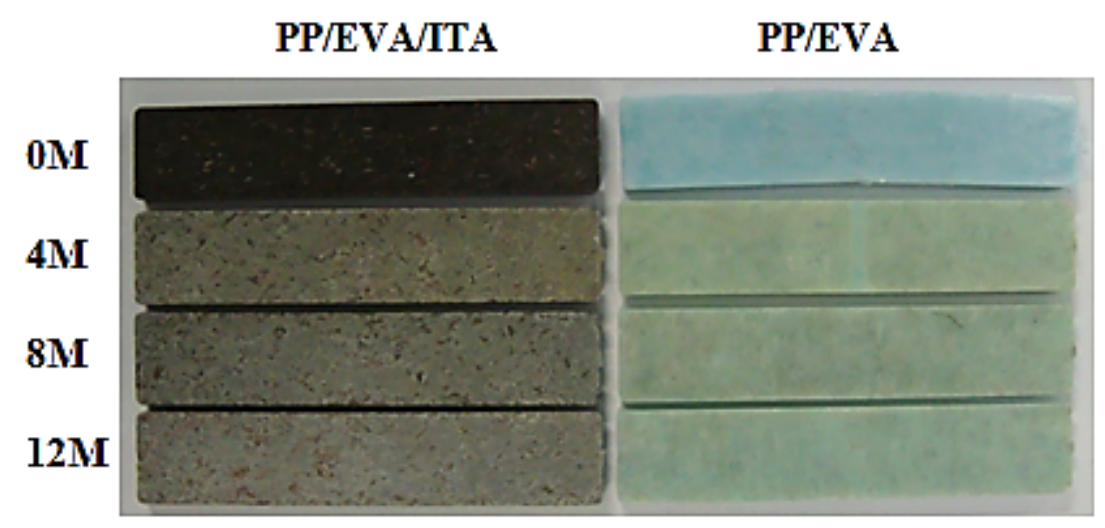

Figure 8: Comparative image of the sample surface as a function of exposure time. 2014-2015.

\section{CONCLUSION}

In this study, the behavior of thermoplastic composites with wood fiber for various outdoor applications was investigated under natural ageing. The exposure to natural weathering and climatic conditions of the period to which the samples were exposed directly affected the degradation of materials. After 365 days of outdoor weathering, an increase of $127 \%$ on elastic modulus was observed for recycle polypropylene/etylene vinyl acetate (PP/EVA) and of 33\% for recycled polypropylene/etylene vinyl acetate/wood flour composites 
(PP/EVA/ITA). However, a decrease of $65 \%$ on tension strength at break for PP/EVA could be noted and for the composite (PP/EVA/ITA) it was $42 \%$. Regarding the tension strain at break, a reduction of $97 \%$ was observed to PP/EVA and 39\% to PP/EVA/ITA. As well, after four months of natural ageing several micro fissures on materials surface could be seen by SEM images. However, PP filled wood flour samples retained a higher fraction of the original mechanical properties after natural ageing, when compared to polypropylene with EVA samples, indicating that in the form of the composite the material tends to be more stable. These results show, on average, an advantage of the composites in comparison to the unfilled, neat polymer, when subjected to natural ageing. However, it has been pointed out that this is probably due to the lower amount of polymer used and to the fact that the photooxidation mainly affects the polymer itself. Also, it was possible to observe a fading on the surface of samples. Thus, the addition of a UV absorber would be necessary to avoid discoloration and a compatibilizer should be used to enhance mechanical properties of composites, or the use of fibers chemically treated. The overall result highlights effects of composition and new information to facilitate development of engineering performance of composite materials, applying in exterior environments.

\section{ACKNOWLEDGEMENT}

This work was supported by the National Council for Scientific and Technological Development, CNPqPROPESQ and the Higher Education Personnel Improvement Coordination (CAPES). The authors also acknowledge the Polymeric Materials Lab (LAPOL), the Federal University of Rio Grande do Sul (UFRGS) and Brazilian Technology Service from Sanitation Network (RESAG-SIBRATEC).

\section{BIBLIOGRAPHY}

[1] KAMDEM, D.P., JIANG, H., et al., "Properties of wood plastic composites made of recycled HDPE and wood flour from CCA-treated wood removed from service", Composites Part A: Applied Science and Manufacturing. v.35, n.3, 347-355, 2004.

[2] VALENTE, M., SARASINI, F., et al., "Hybrid recycled glass fiber/wood flour thermoplastic composites: Manufacturing and mechanical characterization", Composites Part A: Applied Science and Manufacturing., v.42, n.6, 649-657, 2011.

[3] NAGHMOUCHI, I., MUTJÉ, P., et al., "Olive stones flour as reinforcement in polypropylene composites: A step forward in the valorization of the solid waste from the olive oil industry", Industrial Crops and Products, v.72, 183-191, 2015.

[4] STARK, N.M., "Effect of weathering cycle and manufacturing method on performance of wood flour and high-density polyethylene composites", Journal of Applied Polymer Science, v.100, n.4, 3131-3140 , 2006.

[5] FABIYI, J.S., MCDONALD, A.G., et al., "Wood modification effects on weathering of HDPE-based wood plastic composites", Journal of Polymers and the Environment., v.17, n.1, 34-48 , 2009.

[6] HAMDAN, S., ISLAM, M.S., et al., "Study on thermal and biodegradation resistance of tropical wood material composites", Journal of Applied Polymer Science., v.128, n.3, 1842-1847 , 2012.

[7] CATTO, A.L., MONTAGNA, L.S., et al., "Abiotic and biotic degradation of post-consumer polypropylene/ethylene vinyl acetate: Wood flour composites exposed to natural weathering", Polymer Composites, n.May, n/a-n/a, May 2015.

[8] STARK, N.M. AND MATUANA, L.M., "Surface chemistry changes of weathered HDPE/wood-flour composites studied by XPS and FTIR spectroscopy", Polymer Degradation and Stability, v.86, n.1, 1-9, 2004.

[9] LA MANTIA, F.P. AND MORREALE, M., "Accelerated weathering of polypropylene/wood flour composites", Polymer Degradation and Stability, v.93, n.7, 1252-1258 , July 2008.

[10] STARK, N.M., MATUANA, L.M., et al., "Effect of processing method on surface and weathering characteristics of wood-flour/HDPE composites", Journal of Applied Polymer Science, v.93, n.3, 1021-1030, 2004.

[11] PENG, Y., LIU, R., et al., "Effects of UV weathering on surface properties of polypropylene composites reinforced with wood flour, lignin, and cellulose", Applied Surface Science, v.317, 385-392, 2014.

[12] CHAOCHANCHAIKUL, K., JAYARAMAN, K., et al., "Influence of lignin content on photodegradation in wood/HDPE composites under UV weathering", BioResources, v.7, n.1, 38-55, 2012.

[13] FECHINE, G.J.M., SANTOS, J.A.B., et al., "Avaliação da fotodegradação de poliolefinas através de exposição natural e artificial”, Química Nova, v.29, n.4, 674-680 ,July 2006. 
[14] SOCCALINGAME, L., PERRIN, D., et al., "Reprocessing of artificial UV-weathered wood flour reinforced polypropylene composites", Polymer Degradation and Stability, v.120, 313-327, 2015.

[15] ASTM INTERNATIONAL, "D638: Standard test method for tensile properties of plastics", Annual Book of ASTM Standards. n.C, 1-16 (2010).

[16] ASTM INTERNATIONAL, D790: Standard Test Methods for Flexural Properties of Unreinforced and Reinforced Plastics and Electrical Insulating Materials. Annual Book of ASTM Standards, 1-12, 2015.

[17] BRANDRUP, J., IMMERGUT, E.H., et al., Polymer handbook, 4th ed., Wiley-Interscience, 1999.

[18] ASTM INTERNATIONAL, "D2244: Standard Practice for Calculation of Color Tolerances and Color Differences from Instrumentally Measured Color Coordinates" Annual Book of ASTM Standards. 1-10 (2014).

[19] ASTM INTERNATIONAL, "D1435: Standard Practice for Outdoor Weathering of Construction Seals and Sealants" Annual Book of ASTM Standards. 2-5 , 2013.

[20] HOMKHIEW, C., RATANAWILAI, T., et al., "Effects of natural weathering on the properties of recycled polypropylene composites reinforced with rubberwood flour", Industrial Crops and Products, v.56, 52 59, 2014.

[21] BUTYLINA, S., HYVÄRINEN, M., et al., "A study of surface changes of wood-polypropylene composites as the result of exterior weathering", Polymer Degradation and Stability, v.97, n.3, 337-345, March 2012.

[22] NIE, H.-Y., WALZAK, M.., et al., "Atomic force microscopy study of polypropylene surfaces treated by UV and ozone exposure: modification of morphology and adhesion force", Applied Surface Science, v.144, 627-632, 1999.

[23] QIU, W., ZHANG, F., et al., "Preparation and characteristics of composites of high-crystalline cellulose with polypropylene: Effects of maleated polypropylene and cellulose content", Journal of Applied Polymer Science, v.87, n.2, 337-345, January 2003.

[24] BEG, M.D.H. AND PICKERING, K.L., "Accelerated weathering of unbleached and bleached Kraft wood fibre reinforced polypropylene composites", Polymer Degradation and Stability, v.93, n.10, 19391946, 2008.

[25] LÓPEZ-NARANJO, E.J., ALZATE-GAVIRIA, L.M., et al., "Effect of biological degradation by termites on the flexural properties of pinewood residue/recycled high-density polyethylene composites", Journal of Applied Polymer Science. v.128, n.5, 2595-2603 , 2013.

[26] POLETTO, M., "Thermal degradation and morphological aspects of four wood species used in lumber industry”, Revista Árvore, v.40, n.5, 941-948, 2016.

[27] BOCKHORN, H., HORNUNG, A., et al., "Kinetic study on the thermal degradation of polypropylene and polyethylene", Journal of Analytical and Applied Pyrolysis, v.48, n.2, 93-109 , Jan. 1999. 